\title{
NON-LINEAR NUMERICAL MODELS FOR PREDICTING THE BOND STRENGTH OF FIBRE-REINFORCED CONCRETE AT HIGH TEMPERATURES
}

\author{
FRANCISCO B. VARONA ${ }^{1}$, YOLANDA VILLACAMPA ${ }^{2}$, FRANCISCO JOSÉ NAVARRO-GONZÁLEZ², \\ DAVID BRU $^{1} \&$ FRANCISCO JAVIER BAEZA $^{1}$ \\ ${ }^{1}$ Department of Civil Engineering, University of Alicante, Spain \\ ${ }^{2}$ Department of Applied Mathematics, University of Alicante, Spain
}

\begin{abstract}
The steel to concrete bond mechanism is critical to address the behaviour of reinforced concrete structural members. Although this mechanism can be compromised during a fire, it may be one of the least researched phenomena in concrete technology and is not addressed in the design codes and standards. In this work, we present a thorough review of the experimental data available on this topic, focusing on fibre-reinforced concrete. The data allow us to study the evolution of the bond strength as a function of three variables: the exposure temperature, the type of fibre and the volume fraction. A linear multiple regression is initially carried out, followed by a series of non-linear numerical models. These models are built using a methodology based on the finite element method combined with the formulation of the Galerkin method. The numerical models have been developed for different degrees of complexity. The error measurements obtained with the linear regression and the numerical models are compared in order to present a prediction model. The selected model is then validated for different values of the independent variables. This process supports the discussion of the influence that the independent variables have in the evolution of the bond strength between steel reinforcement and fibrereinforced concretes exposed to high temperatures.
\end{abstract}

Keywords: fibre-reinforced concrete, high temperature, bond strength, non-linear numerical models.

\section{INTRODUCTION}

Reinforced concrete (RC) became a structural material during the second half of the 19th century. Reportedly, one of several reasons was its good behaviour exposed to the high temperatures in accidental fire situations, especially when compared to other construction materials of that age, e.g. wrought iron. Concrete exhibits better fire performance than structural steel and recent history provides some notable though dramatic examples for this assertion: the fire in Windsor Tower (Madrid, 2005) and the fire in Grenfell Tower (London, 2017).

The behaviour of concrete exposed to high temperature has been thoroughly researched during the 20th century. One of the earliest pieces of research dates from 1920 [1]. The effects of the exposure of concrete to elevated temperatures can be described through the following stages [2]: (i) drying of capillary water occurs between 20 and $100^{\circ} \mathrm{C}$, with a slight reduction of the compressive strength; (ii) for temperatures up to $300^{\circ} \mathrm{C}$, an increase of the compressive strength is reported for young and dry concretes; (iii) the dehydration of the Calcium-Silicate-Hydrate gel starts around $150-180^{\circ} \mathrm{C}$ and the dehydration of the portlandite takes place between 400 and $600^{\circ} \mathrm{C}$; (iv) a notorious drop of the mechanical properties of concrete is observed in the interval $300-650^{\circ} \mathrm{C}$; (v) in the case of quartzitic aggregates, the transformation of $\alpha$-quartz into $\beta$-quartz takes place at $570^{\circ} \mathrm{C}$ and entails a volumetric increase which is thought to be responsible for the higher drop of mechanical properties in concretes made with this type of aggregates as compared to other types; (vi) the decarbonation of limestone aggregates occurs between 600 and $900^{\circ} \mathrm{C}$; (vii) by $700^{\circ} \mathrm{C}$ the dehydration of the $\mathrm{CSH}$ gel is mostly complete; (viii) the rate of reduction of mechanical 
properties slows down for temperatures higher than $650^{\circ} \mathrm{C}$; (ix) melting of some types of aggregates takes place at around $1200^{\circ} \mathrm{C}$ and melting of the Portland cement paste is reported at around $1350^{\circ} \mathrm{C}$.

Thermal spalling is one of the major concerns in concrete structures exposed to fire. This phenomenon can be described as the progressive separation of surface and outer cover of a concrete member when heated. This process can be either prolonged or sudden and violent. The latter is known as explosive spalling and is typical of dense or compact microstructures - e.g., high strength concrete and self-compacting concrete [3]-[6] - and is also likely to occur at high rates of heating [2]. In this regard, notable fire catastrophes can be mentioned, such as fire in the Eurotunnel of the English Channel in 1996, the Tauern tunnel in 1999 (Austria) and the Mont Blanc tunnel in 1999 (France). In these examples, the thermal exposure in a confined environment, and with a high combustible charge, caused a fast temperature rise, which led to severe concrete damage and explosive spalling. Thus, the structural section was rapidly reduced and inner layers became exposed, hence compromising the structural safety. Another cause of spalling is associated with the thermal gradients and the thermal incompatibility of the different components of the reinforced concrete elements: the cement paste, the aggregates, the steel rebars and tendons [7], [8], which have different coefficients of thermal expansion. Another cause of spalling is the pore pressure increase due to the water steam expelled by the dehydration of the $\mathrm{CSH}$ gel and the portlandite. And yet another cause suggested in [9] is the calcination of $\mathrm{CaCO}_{3}\left(600-900^{\circ} \mathrm{C}\right)$ when calcareous aggregates are used; this chemical process expels $\mathrm{CO}_{2}$ and may contribute to the pore pressure increase.

In the last two decades research has been focused on studying fibre-reinforced concrete exposed to high temperatures. Polypropylene fibres - which melt at approximately $170^{\circ} \mathrm{C}-$ have been proven adequate to control the spalling of concrete. Their melting creates an additional capillary pore network inside the concrete, which allows the release of the water steam generated by dehydration reactions [10], [11]. Thus, the main objective of polypropylene fibres is not the structural reinforcement but rather the improvement of the fire resistance of concrete. On the other hand, steel fibres may be used in order to increase the residual strength of concrete after exposure to elevated temperatures [12], [13]. However, some authors [11] argue that the benefit of adding steel fibres may not be so obvious, since they contribute to speeding up the heating of the concrete and may be prone to producing internal micro-cracking because of thermal incompatibility with the concrete matrix. Hybrid fibre addition (steel and polypropylene) has been addressed in some recent research [10], [11], [14]-[17] and the experimental evidences suggest a synergy between both types of fibre, enhancing the mechanical properties of concrete.

Concrete fire design is covered by international codes and standards, such as the Model Code 2010 [18] and Eurocode 2 [19]. Simplified approaches are proposed as well as more advanced methods based on tables or curves that describe the evolution of the compressive strength of concrete and other properties at high temperatures. A basis for advanced numerical modelling methods is also provided.

Nonetheless, the loss of bond between the steel reinforcement and the concrete during or after exposure to elevated temperatures is not addressed in those standards. The structural strength of a RC element highly depends on an appropriate bond between reinforcement and concrete. This mechanism can be compromised during a fire, because important temperature gradients within the structural element may appear due to the difference in thermal conductivity of concrete and steel. Steel to concrete bond at high temperatures may be one of the least investigated phenomena in concrete research. The evolution of the bond strength between steel reinforcement and fibre reinforced concrete exposed to high temperature has 
been studied and reported in [20]-[23]. The objective of this paper is to analyse the experimental evidence reported in those four references and to work out a predictive model for the bond strength in fibre-reinforced concrete after exposure to a target temperature as a function of several variables. The predictive model is built using a methodology based on the finite element method combined with the formulation of the Galerkin method.

\section{METHODOLOGY}

This section is comprised of two parts. First, we present the four experimental studies on the bond strength in fibre-reinforced concrete exposed to elevated temperatures. The independent variables of the numerical models will be selected from those studies. The second part introduces the numerical model which constitutes the basis for the predictive model.

\subsection{Experimental studies}

The data used to study the evolution of the bond strength at high temperature are collected from the following experimental campaigns:

- Haddad et al. (2008) [20]. High strength concrete specimens were tested. The shape of the specimens was prismatic $(10 \times 10 \times 40 \mathrm{~cm})$ and they included longitudinal and transverse reinforcement. The following types of fibres were added to the concrete admixtures: polypropylene fibres (PP), steel fibres of the hook end type (S) and brass coated steel fibres (BCS, with a very small diameter of $0.15 \mathrm{~mm}$ and a length of $6 \mathrm{~mm}$ ). Four fibre-reinforced admixtures were prepared: Ref-1-A using steel fibres, Ref-1-B using hybrid fibres (S and PP), Ref-1-C using hybrid fibres (S and BCS) and Ref-1-D using BCS fibres. Exposure at high temperature was tested at $350,500,600$ and $700^{\circ} \mathrm{C}$. The target temperature in each test was maintained for 2 hours, to reach a homogeneous thermal state in the specimens.

- Varona et al. (2015) [21]. Normal strength and high strength concrete specimens were tested. In order to facilitate a homogeneous heating, specimens were cylindrical. The geometry of the specimens was based on the RILEM pull-out test as described in Windisch [24]. Samples with $10 \mathrm{~mm}$ diameter bars had a diameter of $100 \mathrm{~mm}$ whilst samples with $12 \mathrm{~mm}$ diameter bars had a diameter of $120 \mathrm{~mm}$. In all cases the height of the specimens was equal to the diameter. The following types of fibres were tested: hook end type steel fibres (S) and polypropylene fibres (PP, with a diameter of $0.035 \mathrm{~mm}$ and a length of $12 \mathrm{~mm}$ ). Three fibre-reinforced batches were prepared: Ref-2-A was a normal strength concrete with steel fibres; Ref-2-B was a high strength concrete with PP fibres; and Ref-2-C was a high strength concrete using a mix of steel and PP fibres. Exposure at high temperature was tested at 450,650 and $825^{\circ} \mathrm{C}$. The target temperatures were maintained for 75 minutes.

- Lublóy and Hlavička (2017) [22]. High strength concrete cylindrical specimens were tested. The diameter and height of the specimens was $120 \mathrm{~mm}$ and $100 \mathrm{~mm}$, respectively. Two fibre-reinforced concretes were prepared: Ref-3-A using steel fibres and Ref-3-B using polypropylene fibres (diameter of $0.032 \mathrm{~mm}$ and a length of $18 \mathrm{~mm}$ ). Exposure at high temperature was tested at 50, 150, 300, 500, 600 and $800^{\circ} \mathrm{C}$. The target temperatures were maintained for 2 hours.

- Varona et al. (2018) [23]. This study is similar to [21]. Only $12 \mathrm{~mm}$ diameter bars were considered (cylindrical specimens with a diameter of $120 \mathrm{~mm}$ and a height of $120 \mathrm{~mm}$ ). Apart from polypropylene fibres, two types of hook end steel fibres were considered: one with a diameter of $0.75 \mathrm{~mm}$ and an aspect ratio of 47 (type $\mathrm{S} 1$ ) and 
another with a diameter of $0.35 \mathrm{~mm}$ and an aspect ratio of 86 (type S2). Three normal strength fibre-reinforced concrete batches were tested: Ref-4-A using PP fibres, Ref4-B using a mix of S1 and PP fibres and Ref-4-C using S2 and PP fibres. Additionally, three high strength fibre-reinforced concrete batches were tested: Ref4-D using PP fibres, Ref-4-E using S1 and PP fibres and Ref-4-F using S2 and PP fibres. Exposure at high temperature was tested at 450,650 and $825^{\circ} \mathrm{C}$. The target temperatures were maintained for 75 minutes.

Further information is given in Tables 1 and 2. Apart from the temperature, eight possible independent variables are identified in Tables 1 and 2.

Table 1: Experimental studies. Variables 1 to 4.

\begin{tabular}{|l|c|c|c|c|}
\hline Reference & $\begin{array}{c}\text { Variable 1 } \\
\text { Strength } \mathrm{f}_{\mathrm{c}, 20^{\circ} \mathrm{C}} \\
(\mathrm{MPa})\end{array}$ & $\begin{array}{c}\text { Variable 2 } \\
\text { Type of fibre }\end{array}$ & $\begin{array}{c}\text { Variable 3 } \\
\text { Volume fraction }\end{array}$ & $\begin{array}{c}\text { Variable 4 } \\
\text { Bar diameter } \\
(\mathrm{mm})\end{array}$ \\
\hline Ref-1-A & 89.8 & $\mathrm{~S}$ & $2 \%$ & 20 \\
\hline Ref-1-B & 85.5 & $\mathrm{~S}+\mathrm{PP}$ & $2 \%$ & 20 \\
\hline Ref-1-C & 93.7 & $\mathrm{~S}+\mathrm{BCS}$ & $2 \%$ & 20 \\
\hline Ref-1-D & 103.6 & $\mathrm{BCS}$ & $2 \%$ & 20 \\
\hline Ref-2-A & 31.0 & $\mathrm{~S}$ & $0.25 \%$ & 10 \\
\hline Ref-2-B & 84.9 & $\mathrm{PP}$ & $0.33 \%$ & 12 \\
\hline Ref-2-C & 89.5 & $\mathrm{~S}+\mathrm{PP}$ & $0.58 \%$ & 12 \\
\hline Ref-3-A & 63.6 & $\mathrm{PP}$ & $0.11 \%$ & 12 \\
\hline Ref-3-B & 75.1 & $\mathrm{~S}$ & $0.45 \%$ & 12 \\
\hline Ref-4-A & 29.0 & $\mathrm{PP}$ & $0.16 \%$ & 12 \\
\hline Ref-4-B & 19.1 & $\mathrm{~S}+\mathrm{PP}$ & $0.41 \%$ & 12 \\
\hline Ref-4-C & 24.6 & $\mathrm{~S}+\mathrm{PP}$ & $0.41 \%$ & 12 \\
\hline Ref-4-D & 89.0 & $\mathrm{PP}$ & $0.27 \%$ & 12 \\
\hline Ref-4-E & 97.6 & $\mathrm{~S}+\mathrm{PP}$ & $0.52 \%$ & 12 \\
\hline Ref-4-F & 83.4 & $\mathrm{~S}+\mathrm{PP}$ & $0.52 \%$ & 12 \\
\hline
\end{tabular}

Table 2: Experimental studies. Variables 5 to 8.

\begin{tabular}{|l|c|c|c|c|}
\hline Reference & $\begin{array}{c}\text { Variable 5 } \\
\text { Bond length to } \\
\text { diameter } \\
\text { (ratio) }\end{array}$ & $\begin{array}{c}\text { Variable 6 } \\
\text { Concrete cover to } \\
\text { diameter } \\
\text { (ratio) }\end{array}$ & $\begin{array}{c}\text { Variable 7 } \\
\text { Age at test } \\
\text { (days) }\end{array}$ & $\begin{array}{c}\text { Variable 8 } \\
\text { Time at max. } \\
\text { temperature }\end{array}$ \\
\hline Ref-1-A to D & 7.5 & 2 & 35 & 2 hours \\
\hline Ref-2-A & 5 & 4.5 & 60 & $75 \mathrm{~min}$ \\
\hline Ref-2-B \& C & 4.17 & 4.71 & 60 & $75 \mathrm{~min}$ \\
\hline Ref-3-A \& B & 3.33 & 4.5 & 28 & 2 hours \\
\hline Ref-4-A to F & 4.17 & 4.71 & 60 & $75 \mathrm{~min}$ \\
\hline
\end{tabular}

In all cases bond strength was measured after cooling to room temperature (around $20^{\circ} \mathrm{C}$ ). Cooling was natural, not forced with water immersion or spraying. The bond strength $\tau_{b}$ was obtained through eqn (1): 


$$
\tau_{b}=\frac{P}{\pi D l_{b}},
$$

where $P$ is the maximum pull-out load, $D$ is the diameter of the embedded bar and $l_{b}$ is the bond length.

\subsection{Numerical modelling}

The numerical methodology is based on Galerkin's formulation of the finite element method [25], [26] and allows us to obtain predictive models for the relationship between variables that have been defined a priori. As is usual in the finite element method, a geometric model of finite elements is generated so that the model is defined by its value at the nodes of the elements [27]. In this way, for each finite element mesh defined in a hyper-cube, a numerical model is generated. Galerkin's formulation of the finite element method improves the computational efficiency of algorithms from other methodologies based on geometric models of finite elements, as reported in [28], [29]. The finite element mesh is characterized by its complexity index, which is defined as the number of elements defined along each edge of the hyper-cube. The total number of nodes is thus a function of the complexity index. In this way, a numerical model is generated for each set of experimental data and for each complexity. The use of Galerkin's formulation of the finite element method and the corresponding improvement in computational efficiency allows us to analyse relationships with a greater number of variables and relationships in which complexity needs to be increased without involving much time in the execution of the software.

Bond strength at high temperature is the dependent variable. Amongst the independent variables, the fundamental one is the target temperature or maximum exposure temperature. The experimental methodologies applied in the reports introduced in previous section are consistent and it is possible to identify eight additional independent variables, presented in Tables 1 and 2. The number of independent variables to be considered in the numerical models strongly depend on the data available. The number of data points is calculated below.

- Each of the four references Ref-1-A to D provides bond strength values at the following temperatures: $20,350,500,600$ and $700^{\circ} \mathrm{C}$ (5 targets). Therefore, the number of data points is $4 \times 5=20$.

- Each of the three references Ref-2-A to $\mathrm{C}$ provides bond strength values at the following temperatures: $20,450,650$ and $825^{\circ} \mathrm{C}$ (4 targets). Therefore, the number of data points is $3 \times 4=12$.

- Each of the two references Ref-3-A \& B provides bond strength values at the following temperatures: $20,50,150,300,500,600$ and $800^{\circ} \mathrm{C}$ ( 7 targets). Therefore, the number of data points is $2 \times 7=14$.

- And each of the six references Ref-4-A to F provides bond strength values at the following temperatures: $20,450,650$ and $825^{\circ} \mathrm{C}$ (4 targets). Therefore, the number of data points is $6 \times 4=24$.

This gives a total of $20+12+14+24=70$ data points, so the number of variables should not be greater than three - at least 15 to 25 data points per variable are usually recommended. Since the target temperature is the fundamental independent variable, two more variables may be chosen. The data points are shown in Fig. 1 as a function of the target temperature. Given that the study is focused on fibre-reinforced concretes, the volume fraction seemed to be a natural option. The third independent variable is the type of fibres, because they have 
different effects on the endurance of concrete exposed to high temperatures - the influence of polypropylene fibres is arguably radically different from the influence of steel fibres. Therefore, the following independent variables were selected:

- Variable 1: type of fibre. It is a categorical variable with three discrete values: 1 (steel fibre), 2 (polypropylene fibre) and 3 (hybrid fibre).

- Variable 2: volume fraction. It is a numerical variable, expressed in percentage.

- Variable 3: exposure temperature. It is a numerical variable, expressed in ${ }^{\circ} \mathrm{C}$.

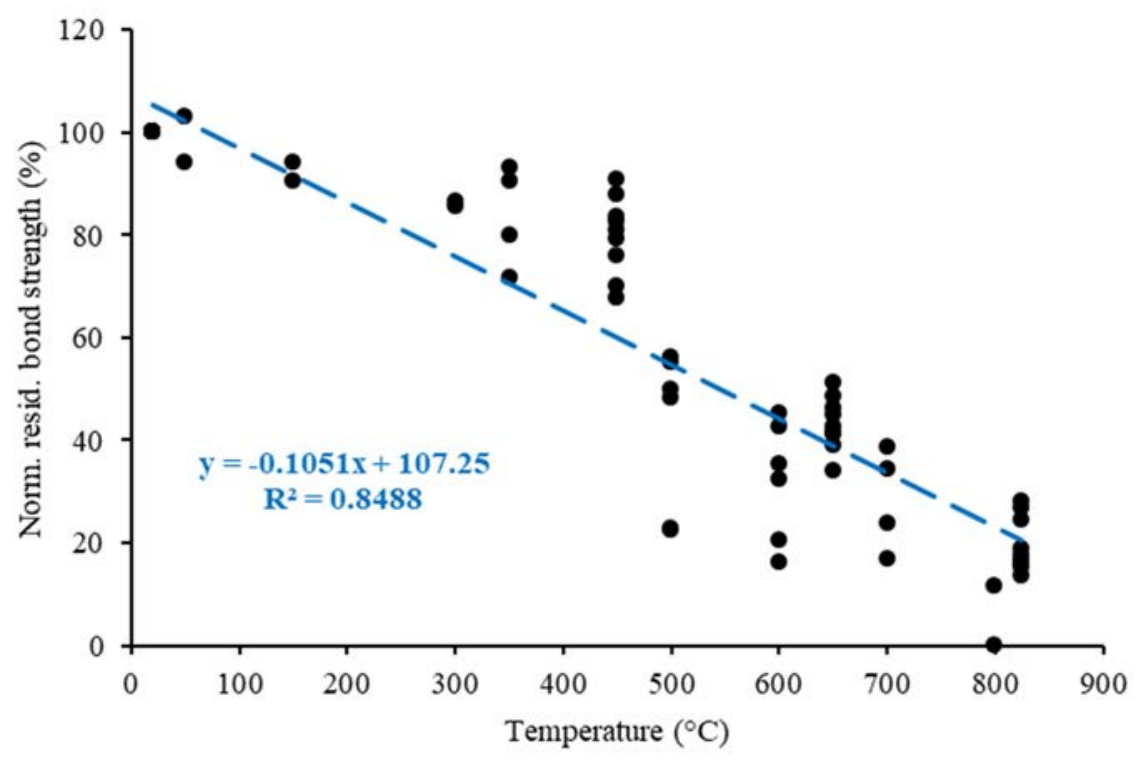

Figure 1: Experimental data points available and linear regression analysis.

\section{RESULTS AND DISCUSSION}

This section is divided into two parts. In the first part we apply regression analyses to study the evolution of the bond strength at high temperature based on experimental evidence. We also show the error parameters obtained with each technique in order to select the appropriate one. In the second part we present design curves of the evolution of the bond strength at high temperature, which are based on the regression method selected.

\subsection{Regression analyses and error parameters}

Linear regression was the first type of analysis carried out, with the exposure temperature as the independent variable. The 70 available data points and the linear regression analysis are presented in Fig. 1. The vertical axis in Fig. 1 is the normalised residual bond strength after exposure to high temperature, i.e. the percentage of the bond strength after heating and cooling with respect to the bond strength at ambient temperature.

Next, linear multiple regression was performed. The independent variables were the target or exposure temperature, the type of fibre and the fibre volume fraction. The result is shown in eqn (2): 


$$
\frac{\tau_{b, T}}{\tau_{b, 20^{\circ} \mathrm{C}}}=\frac{1}{100}(99.59-0.1061 \mathrm{~T}+3.877 \mathrm{FT}-0.5588 \mathrm{VF}),
$$

where: $\tau_{b, T}$ is the residual bond strength after exposure to temperature $T ; \tau_{b, 20^{\circ} \mathrm{C}}$ is the bond strength at ambient temperature; $T$ is the exposure temperature in ${ }^{\circ} \mathrm{C} ; F T$ is the fibre type $(1$ for steel fibres, 2 for polypropylene fibres and 3 for hybrid fibres); and $V F$ is the fibre volume fraction expressed as percentage. The $R^{2}$ coefficient was 0.857 , slightly increasing with respect to the linear regression analysis (see Fig. 1).

Finally, we applied the numerical modelling based on Galerkin's formulation of the finite element method. In this particular case, the space of solutions is a 4-dimensional hypercube because there are four variables - the dependent variable plus three independent variables. Complexity index $C$ was set at five levels: 40,50, 60, 70 and 80. The meshing of the hypercube is controlled by index $C$ and the mesh resolution was between $40^{3}=64000$ nodes and $80^{3}=512000$ nodes.

Apart from the $\mathrm{R}^{2}$ coefficient, several error measurements were studied. These are calculated through eqns (3) to (7):

$$
\begin{gathered}
\text { MAE }=\frac{\sum_{i=1}^{N}\left|R_{i}-P_{i}\right|}{N}, \\
M A P E=\frac{\sum_{i=1}^{N} \frac{\left|R_{i}-P_{i}\right|}{R_{i}}}{N}, \\
R M S E=\sqrt{\frac{\sum_{i=1}^{N}\left(R_{i}-P_{i}\right)^{2}}{N}}, \\
\varepsilon=\sqrt{\frac{\sum_{i=1}^{N}\left(R_{i}-P\right)^{2}}{N-V}}, \\
\delta=\frac{\sqrt{\frac{1}{N} \sum_{i=1}^{N} R_{i}^{2}}}{\sqrt{N-V}}
\end{gathered}
$$

where: $R_{\mathrm{i}}$ are the real or experimental values of the dependent variable; $P_{i}$ are the predicted values of the dependent variable; $N$ is the number of data points (in this case, $N=70$ ); $V$ is the number of independent variables (in this case, $V=3$ ); $M A E$ is the mean absolute error; $M A P E$ is the mean absolute percentage error; RMSE is the root mean square error; $\varepsilon$ is an error measurement similar to RMSE that penalises the number of independent variables; and $\delta$ is a normalised version of the $\varepsilon$ error. 
Table 3 illustrates how each method performed by showing the $R^{2}$ values and the aforementioned error measurements. MAPE was not finally considered because there were data points where the dependent variable's value was zero or close to zero. The performance of the different types of analysis is graphically compared in Fig. 2.

Table 3: $\mathrm{R}^{2}$ and error measurements of the types of analysis considered.

\begin{tabular}{|c|c|c|c|c|c|}
\hline Type of analysis & $R^{2}$ & MAE & RMSE & $\varepsilon$ & $\delta$ \\
\hline Linear regression & 0.8488 & 9.35 & 12.6 & 12.9 & 0.183 \\
\hline Linear multiple regression & 0.8575 & 9.00 & 12.2 & 12.5 & 0.178 \\
\hline$C=40$ & 0.9863 & 2.91 & 3.79 & 3.87 & 0.055 \\
\hline ๑ & 0.9885 & 2.61 & 3.47 & 3.54 & 0.050 \\
\hline$. \stackrel{\Xi}{\Xi} \stackrel{C}{E}=60$ & 0.9898 & 2.40 & 3.26 & 3.34 & 0.047 \\
\hline 讧 $\stackrel{\circlearrowright}{\circlearrowright} C=70$ & 0.9902 & 2.31 & 3.21 & 3.28 & 0.047 \\
\hline$C=80$ & 0.9904 & 2.27 & 3.17 & 3.24 & 0.046 \\
\hline
\end{tabular}

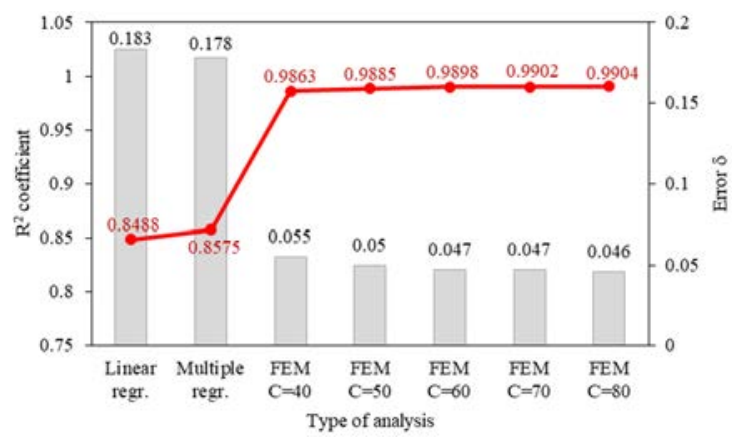

Figure 2: $R^{2}$ coefficient and error $\delta$.

As expected, the numerical modelling techniques outperformed the linear regression methods. The five attempts with the finite element method were capable of explaining around $99 \%$ of the data points. With a complexity of $\mathrm{C}=40$, the numerical model with three independent variables exhibited a $R^{2}$ coefficient in excess of $98 \%$ and was more successful than the multiple linear regression with its $R^{2}$ around $86 \%$. Regarding the complexity index, error $\delta$ seemed to get stabilised at $C=60$. Therefore, the numerical model with $C=60$ was chosen for application.

\subsection{Application of the numerical model}

The application of the numerical model was carried out for the following values of the independent variables:

- Variable 1 encodes the type of fibre and its three discrete values were considered: $v_{1}=1$ (steel fibre), $v_{1}=2$ (polypropylene fibre) and $v_{1}=3$ (hybrid fibre).

- Variable 2 corresponds to the fibre volume fraction percentage and the following values were applied: $v_{2}=0.25 \%, v_{2}=0.5 \%, v_{2}=1 \%, v_{2}=1.5 \%$ and $v_{2}=2 \%$.

- Finally, variable 3 corresponds to the exposure temperature. In addition to the ambient temperature $\left(20^{\circ} \mathrm{C}\right)$, the range between 100 and $800^{\circ} \mathrm{C}$ at intervals of $50^{\circ} \mathrm{C}$ was studied. 
The application is illustrated in Fig. 3: steel fibres, Fig. 4: polypropylene fibres, and Fig. 5: hybrid fibres, e.g. steel and polypropylene.

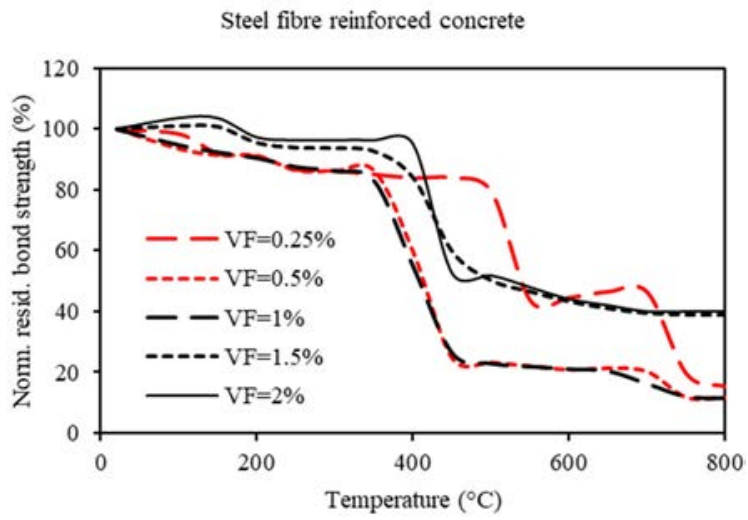

Figure 3: Application of the numerical model for steel fibre-reinforced concretes.

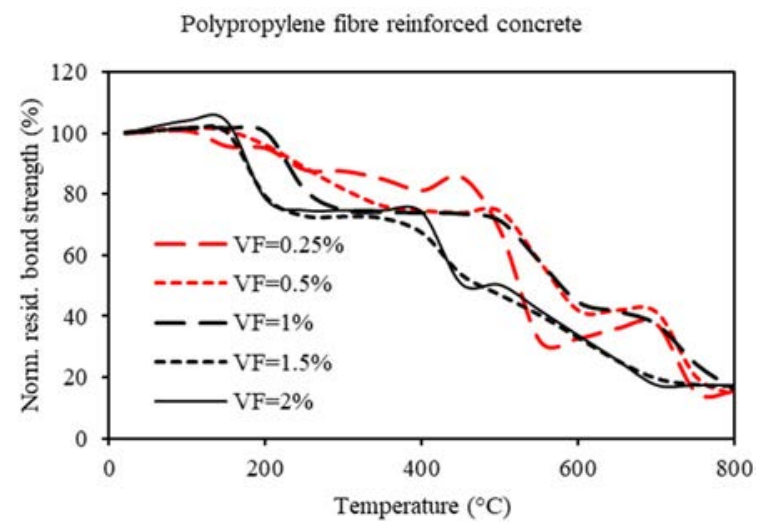

Figure 4: Application of the numerical model for polypropylene fibre-reinforced concretes.

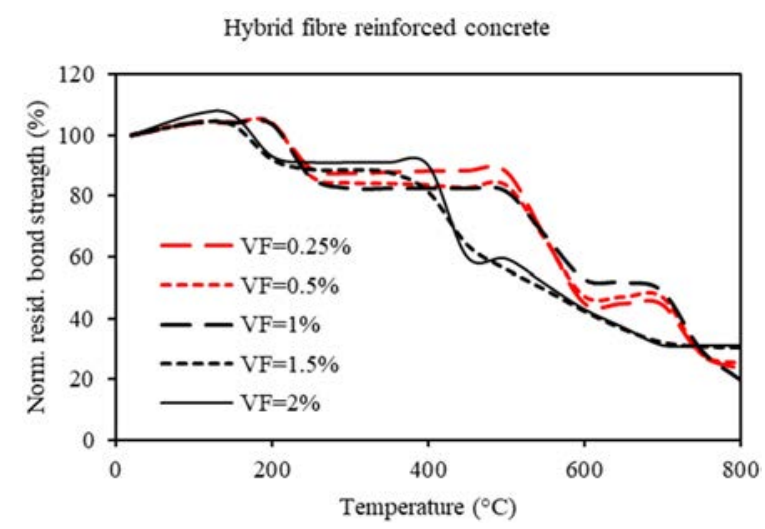

Figure 5: Application of the numerical model for hybrid fibre-reinforced concretes. 
Regardless of the fibre volume fraction, Fig. 3 shows that steel fibre-reinforced concretes seemed to maintain their original bond strength up to temperatures around $400^{\circ} \mathrm{C}$. Over $500^{\circ} \mathrm{C}$, fibre content may have impact on the bond strength. Volume fractions of $1.5 \%$ and $2 \%$ may control the residual bond strength at around $40 \%$ up to $800^{\circ} \mathrm{C}$, whilst concretes with smaller volume fractions dropped below 20\%. An unexpected and strange result was found between 500 and $700^{\circ} \mathrm{C}$, with the smallest volume fraction performing as good as contents of $1.5 \%$ and $2 \%$. This result is difficult to explain and may be a consequence of a bias in the original source of experimental data.

The evolution of the bond strength with the other types of fibres considered was less abrupt (see Fig. 4 and Fig. 5). Both with polypropylene and hybrid fibres and in the 400 $700^{\circ} \mathrm{C}$ range, moderate volume fractions not greater than $1 \%$ seemed to yield better values of the residual bond strength than greater volume fractions up to $2 \%$. In the case of the polypropylene fibres this result is logical, because their melting at $170^{\circ} \mathrm{C}$ produces a capillary network in the concrete matrix. Although this effect is beneficial to the spalling control, an excess in fibre content may weaken the microstructure of the concrete after melting. This phenomenon is also likely to compromise the synergy between steel and polypropylene fibres for total volume fractions over $1 \%$. After exposure to $800^{\circ} \mathrm{C}$, the numerical model estimated that the steel fibre-reinforced concretes with at least $1.5 \%$ of fibre volume fraction exhibited the best residual bond strength (around $40 \%$ ), followed by the hybrid reinforced concretes (around 30\%).

\section{CONCLUSIONS}

The evidence sourced from four experimental studies was used to predict the evolution of the bond strength in fibre-reinforced concretes after exposure to high temperature. The number of data points available allowed us to apply a numerical simulation based on Galerkin's formulation of the finite element method. Different levels of complexity were tested and one of them was selected for application, based on the evolution of the error measurements.

The numerical application helped to bring forth some conclusions regarding the effect of fibre addition on the evolution of bond strength. In the case of steel fibres, volume fraction may have a positive effect at temperatures up to $800^{\circ} \mathrm{C}$. However, in the case of polypropylene fibres, bond strength seemed to get compromised for volume fractions in excess of $1 \%$, which could be attributed to their premature melting at around $170^{\circ} \mathrm{C}$. In the range between 400 and $600^{\circ} \mathrm{C}$, hybrid fibre-reinforced concretes may be expected to exhibit the best performance - in terms of the residual bond strength. Moreover, hybrid fibre content over $1 \%$ did not seem to produce better results.

Some unexpected results require further analysis and, most likely, more exhaustive experimental background. Nonetheless, as new experimental evidence becomes available, the methodology presented here is arguably adequate to refine the prediction models.

\section{ACKNOWLEDGEMENT}

The authors want to acknowledge Generalitat Valenciana, which has made possible this piece of research through the grant GV/2018/015.

\section{REFERENCES}

[1] Lea, F.C., The effect of temperature on some of the properties of materials. Eng., 110(3), pp. 293-298, 1920.

[2] Bazant, Z.P. \& Kaplan, M.F., Concrete at High Temperatures: Material Properties and Mathematical Models, Longman Group Ltd.: Essex, 1996. 
[3] Castillo, C. \& Durrani, A.J., Effect of transient high temperature on high strength concrete. ACI Mater. J., 87(1), pp. 47-53, 1987.

[4] Kodur, V., Fire performance of high-strength concrete structural members. Constr. Technol. Updat., p. 4, 1999.

[5] Sideris, K.K., Mechanical characteristics of self-consolidating concretes exposed to elevated temperatures. J. Mater. Civ. Eng., 19(8), pp. 648-654, 2007.

[6] Anagnostopoulos, N., Sideris, K.K. \& Georgiadis, A., Mechanical characteristics of self-compacting concretes with different filler materials, exposed to elevated temperatures. Mater. Struct., 42(10), pp. 1393-1405, 2009.

[7] Foti, D., Prestressed slab beams subjected to high temperatures. Compos. Part B Eng., 58, pp. 242-250, 2014.

[8] Bailey, C.G. \& Ellobody, E., Whole-building behaviour of bonded post-tensioned concrete floor plates exposed to fire. Eng. Struct., 31(8), pp. 1800-1810, 2009.

[9] Ahmed, A.E., Al-Shaikh, A.H. \& Arafat, T.I., Residual compressive and bond strengths of limestone aggregate concrete subjected to elevated temperatures. Mag. Concr. Res., 44(159), pp. 117-125, 1992.

[10] Peng, G.F., Bian, S.H., Guo, Z.Q., Zhao, J., Peng, X.L. \& Jiang, Y.C., Effect of thermal shock due to rapid cooling on residual mechanical properties of fiber concrete exposed to high temperatures. Constr. Build. Mater., 22(5), pp. 948-955, 2008.

[11] Ding, Y., Azevedo, C., Aguiar, J.B. \& Jalali, S., Study on residual behaviour and flexural toughness of fibre cocktail reinforced self compacting high performance concrete after exposure to high temperature. Constr. Build. Mater., 26(1), pp. 21-31, 2012.

[12] Cheng, F.P., Kodur, V.K.R. \& Wang, T.C., Stress-strain curves for high strength concrete at elevated temperatures. J. Mater. Civ. Eng., 16(1), pp. 84-90, 2004.

[13] Lau, A. \& Anson, M., Effect of high temperatures on high performance steel fibre reinforced concrete. Cem. Concr. Res., 36(9), pp. 1698-1707, 2006.

[14] Poon, C.S., Shui, Z.H. \& Lam, L., Compressive behavior of fiber reinforced highperformance concrete subjected to elevated temperatures. Cem. Concr. Res., 34(12), pp. 2215-2222, 2004.

[15] Varona, F.B., Baeza, F.J., Bru, D. \& Ivorra, S., Influence of high temperature on the mechanical properties of hybrid fibre reinforced normal and high strength concrete. Constr. Build. Mater., 159, pp. 73-82, 2018.

[16] Alberti, M.G., Enfedaque, A.J., Gálvez, C., Cánovas, M.F. \& Osorio, I.R., Polyolefin fiber-reinforced concrete enhanced with steel-hooked fibers in low proportions. Mater. Des., 60, pp. 57-65, 2014.

[17] Ganesan, N., Indira, P.V., \& Sabeena, M.V., Behaviour of hybrid fibre reinforced concrete beam-column joints under reverse cyclic loads. Mater. Des., 54, pp. 686693, 2014.

[18] International Federation for Structural Concrete (fib), Fib Model Code for Concrete Structures 2010, Ernst \& Sohn: Berlin, 2013.

[19] European Committee for Standarisation, Eurocode 2: Design of Concrete Structures Part 1-2: General Rules - Structural Fire Design. AENOR: Madrid, 2011.

[20] Haddad, R.H., Al-Saleh, R.J. \& Al-Akhras, N.M., Effect of elevated temperature on bond between steel reinforcement and fiber reinforced concrete. Fire Saf. J., 43(5), pp. 334-343, 2008.

[21] Varona, F.B., Baeza, F.J., Ivorra, S. \& Bru, D., Experimental analysis of the loss of bond between rebars and concrete exposed to high temperatures. Dyna, 90(1), pp. 7886, 2015. 
[22] Lublóy, E. \& Hlavička, V., Bond after fire. Constr. Build. Mater., 132, pp. 210-218, 2017.

[23] Varona, F.B., Baeza, F.J., Bru, D. \& Ivorra, S., Evolution of the bond strength between reinforcing steel and fibre reinforced concrete after high temperature exposure. Constr. Build. Mater., 176, pp. 359-370, 2018.

[24] Windisch, A., A modified pull-out test and new evaluation methods for a more real local bond-slip relationship. Mater. Struct., 18(105), pp. 181-184, 1985.

[25] Hatami, M., Weighted Residual Methods, 1st ed., Academic Press, 2017.

[26] Zienkiewicz, O., Taylor, R., \& Zhu, J.Z., The Finite Element Method: Its Basis and Fundamentals, 7th ed., Butterworth-Heinemann, 2013.

[27] Villacampa, Y.F., Navarro-González, J. \& Llorens, J., A geometric model for the generation of models defined in complex systems. Ecosystems and Sustainable Development VII, 2009, pp. 71-82.

[28] Navarro-González, F.J. \& Villacampa, Y., A new methodology for complex systems using n-dimensional finite elements. Adv. Eng. Softw., 48, pp. 52-57, 2012.

[29] Navarro-González, F.J. \& Villacampa, Y., A finite element numerical algorithm for modelling and data fitting in complex systems. Int. J. Comput. Methods Exp. Meas., 4(2), pp. 100-113, 2016. 